\title{
Implantação de Projeto de Visita de Animais em Hospital Infantil de Alta Complexidade- Instituto da Criança HCFMUSP
}

\author{
Lara, Jaqueline Aparecida de; Rossi Junior, Alfio; Kudo, Aide Mitie; \\ Pavani, Simone Aparecida Lima; Lopes, Viviane Aparecida; Berti, Eliana Regina \\ Coelho; Ichitani, Tatiane \\ Instituto da Criança do Hospital das Clínicas — jaqueline.lara@hc.fm.usp.br
}

Introdução. a visita de animais no ambiente hospitalar auxilia na melhoria da qualidade de vida do paciente durante o período de internação. Tendo em vista que a atividade visita de animais também chamada de Terapia assistida por animais (A/TAA) tem sido muito utilizada há décadas em instituições reconhecidas nos Estados Unidos, o Instituto da Criança com apoio da Comissão de Controle de Infecção Hospitalar $(\mathrm{CCIH})$ e equipe multidisciplinar do Instituto da Criança, implantou o projeto Cão Terapeuta em parceria com uma Organização não Governamental chamada também Cão Terapeuta. Objetivo; o projeto tem como objetivo fazer com que a criança desvie o foco da doença e possa ter momentos de descontração, socialização e alegria no durante sua permanência no hospital. Além de auxiliar no desenvolvimento da autoestima e autoconfiança da criança, o mesmo também contribuiu significativamente para a melhoria do ambiente de trabalho nas enfermarias do Instituto. Metodologia: para a implantação do Projeto a Coordenação de Humanização em parceria com a Comissão de Controle de Infecção Hospitalar $(\mathrm{CClH})$ e equipe multidisciplinar do Instituto da Criança desenvolveu um fluxo para acompanhar a entrada, permanência e saída dos animais, bem como um fluxo para autorização médica. Os animais são monitorados pela $\mathrm{CCIH}$ no que diz respeito a estado de saúde do animal, exames parasitológicos a cada três meses e vacinas. As visitas são realizadas de 15 em 15 dias. Resultados: com o acompanhamento do projeto podemos perceber os seguintes resultados: - Maior integração e socialização entre pacientes, acompanhantes e colaboradores. - Afastamento do estado de dor do paciente. - Melhoria da autoconfiança diante do enfrentamento da doença • Recreação, diversão e afastamento do isolamento. • Encorajamento das funções da fala • Estímulo à memória Conclusão: Levando-se em consideração que o Instituto da Criança é um Hospital de alta complexidade que atende crianças de 0 a 18 anos com doenças crônicas e raras, algumas crianças tiveram contato com um cachorro pela primeira vez devido ao longo período de internação. a visita de animais colaborou para a melhoria das relações e da comunicação entre os usuários e profissionais de saúde.

Lara, Jaqueline Aparecida de; Rossi Junior, Alfio; Kudo, Aide Mitie; Pavani, Simone Aparecida Lima; Lopes, Viviane Aparecida; Berti, Eliana Regina Coelho; Ichitani, Tatiane. Implantação de Projeto de Visita de Animais em Hospital Infantil de Alta Complexidade- Instituto da Criança HCFMUSP. In: Anais do Congresso Internacional de Humanidades \& Humanização em Saúde [= Blucher Medical Proceedings, num.2, vol.1]. São Paulo: Editora Blucher, 2014. ISSN 2357-7282 DOI 10.5151/medpro-cihhs-10600 